\title{
Semânticas do envelhecimento modos de envelhecer nos anos 70
}

\author{
Monique Borba Cerqueira \\ Aline Ângela Victoria Ribeiro
}

\section{SciELO Books / SciELO Livros / SciELO Libros}

CERQUEIRA, M. B., and RIBEIRO, A. Â, V. Semânticas do envelhecimento modos de envelhecer nos anos 70. In: D'ALENCAR, R. S., ed. A representação social na construção da velhice [online]. Ilhéus, BA: EDITUS. 2017, pp. 15-36. ISBN: 978-85-7455-486-0. https://doi.org/10.7476/9788574554860.0002.

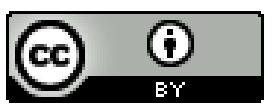

All the contents of this work, except where otherwise noted, is licensed under a Creative Commons Attribution 4.0 International license.

Todo o conteúdo deste trabalho, exceto quando houver ressalva, é publicado sob a licença Creative Commons Atribição 4.0.

Todo el contenido de esta obra, excepto donde se indique lo contrario, está bajo licencia de la licencia Creative Commons Reconocimento 4.0. 


\title{
SEMÂNTICAS DO ENVELHECIMENTO - MODOS DE ENVELHECER NOS ANOS 70
}

\author{
Monique Borba Cerqueira \\ Aline Ângela Victoria Ribeiro
}

\section{Introdução}

Este trabalho tematiza mudanças na paisagem do envelhecimento no Brasil, ao longo dos anos 70, a partir do novo contexto social e institucional inscrito na produção de hábitos e valores que transformaram todo um grupo de idade, instaurando novos padrões normativos na rotina dos mais velhos.

Trata-se de analisar notícias no intervalo de tempo de dez anos, fazendo um paralelo entre a trajetória de matérias publicadas nas páginas da Revista Veja e o seu desdobramento futuro, expresso na produção de conhecimento sobre o envelhecimento nos dias atuais. Todas as edições da Veja que tematizaram o envelhecimento no período repercutiram socialmente e remeteram a problematizações, novas perspectivas e visibilidades sobre a velhice e o processo de envelhecer.

Examinar o momento de transição em que os mais velhos ensaiam sua emergência como sujeitos sociais em um cenário de longo assujeitamento na vida nacional, significa verificar as principais mudanças, consequências e agentes sociais envolvidos nesse processo. Importa saber 
qual o significado das transformações simbólicas sofridas pelos grupos longevos registradas numa mídia escrita de grande apelo popular.

A ideia de representação social aparece aqui não apenas explicitando o real como fato evidenciado na cultura, mas no caso de um veículo de comunicação, como geradora de opiniões, conhecimento e convencimento social.

Com efeito, nas últimas décadas, a noção de representação social toma novo fôlego a partir da necessidade de explicar a crescente importância da dimensão cultural nos fenômenos sociais de toda ordem (JUNQUEIRA, 2005, p. 145).

Nessa direção, nosso interesse é compreender a dinâmica das representações sociais no sentido de "avaliar a realidade social a partir da cultura, suas surpresas e engrenagens" (JUNQUEIRA, 2005, p.146). Uma visão analítica das experiências e trajetórias do envelhecimento contemporâneo é o que propomos fazer como contraponto aos temas publicados pela Revista Veja, estabelecendo uma estratégia prospectiva quanto aos problemas do envelhecer.

Não há dúvida de que a imparcialidade da mídia é um mito desprovido de qualquer sentido nos dias atuais. O debate público sobre temas de extrema importância para a sociedade tem sido objeto de viés jornalístico na abordagem de diferentes temas, obstruindo interesses coletivos e individuais.

Segundo a PubliAbril, as plataformas da Veja têm o alcance de cerca de 20 milhões de pessoas ${ }^{1}$. Criada em 1968, Veja é a revista semanal de maior circulação nacional, com uma tiragem superior a um milhão de cópias e uma linha editorial muitas vezes polêmica. Um dos slogans da revista, "Os olhos do Brasil", reflete a pretensão de expressar o conjunto dos problemas da sociedade brasileira.

1 Fonte: PubliAbril, disponivel em: < http://publiabril.abril.com.br/marcas/veja>. Acesso em: 4 set. 2016. 
Ao examinarmos a mídia impressa produzida pela revista, interrogamos sobre o trânsito, a periodicidade e o conteúdo das matérias sobre envelhecimento no contexto social da década de 70. No entanto, é importante ressaltar que a trajetória temática de notícias sobre o envelhecimento no Brasil nas últimas décadas, sua seleção, repetições e ausências, bem como a manifestação de juízos e impressões difusas e contraditórias geradas no público são um fenômeno que perpassa toda a grande mídia e que será objeto de nossa atenção. Ainda assim, a dimensão discursiva é valiosa, uma vez que disponibiliza ao pesquisador a arquitetura social que dá a ver a construção de imagens, identidades e inserções sociais dos nossos maiores protagonistas - mulheres e homens idosos.

\section{Envelhecer na década de $\mathbf{7 0}^{2}$}

Na década de 70 tem início a ressignificação do discurso sobre o envelhecimento que vai conferir virtude e otimismo a todo o universo do envelhecer - medicina, ciência, indústria estética, produção acadêmica, políticas públicas e muito mais. A velhice, transmutada em terceira idade, que até então se confundia com um período sombrio, associado à debilidade fisica e ao fim da vida, passou a representar conforto, sociabilidade e autonomia para os idosos, a partir dos anos 70 .

Nesse período, o envelhecimento passa a ser representado pela questão dos direitos, da dignidade, expectativas promissoras de felicidade e inserção social, baseadas no

2 Entre janeiro de 1970 e dezembro de 1979 foram publicadas 514 edições. Aqui utilizamos 10 reportagens de 10 edições diferentes, representando cerca de $5 \%$ das edições da revista na década em questão (ANEXO A). Ressalta-se que o que se publicou sobre velhos, velhice, envelhecimento e terceira idade foi pouco representativo na comparação com o número de edições publicadas na década de 70 . 
surgimento de atividades lúdicas, recreativas e no desenho de novos valores compartilhados pelos idosos. Tudo isso ocorreu paralelamente à inscrição de demandas que ganharam visibilidade e legitimação na arena politica. Nesse contexto, a Gerontologia emerge com robustez, prenunciando o enorme apetite segundo o qual o setor saúde e, mais especificamente, a medicina, estabeleceria sobre a velhice e os processos de envelhecimento.

Esse momento de fundação de uma nova ótica sobre a velhice vai apresentar uma interseção com o passado, onde se explicitará situações de extremo conservadorismo e preconceito, emprestando negatividade aos idosos. Só posteriormente, com a consolidação da terceira idade, é possivel outorgar, aos poucos, positividade ao envelhecer.

Na edição 185 da Revista Veja, do ano de 1972, a seção "comportamento" traz algumas "pérolas" na redação de uma matéria intitulada "Um mês de verão só para ve1hos". No texto pode-se perceber que a narrativa sobre o envelhecimento não registra nenhuma preocupação com uma linguagem politicamente correta em relação à velhice, antes aponta o predomínio de um discurso pejorativo em relação aos mais velhos, típico do período.

Em março, nos últimos dias da temporada, veranistas que vivem seus últimos verões tomam conta de Guarapari, a $50 \mathrm{~km}$ de Vitória, ES. E a fisionomia da cidade, agitada nos três meses anteriores, se modifica. Em lugar dos rapazes sobre motos e outras máquinas envenenadas, passeiam pacatos velhinhos e velhinhas de bengalas envernizadas. [...] E até as praias mudam de nome. A das Pelotas, quase sem ondas, anunciada no guia turístico como um "cantinho delicioso de mar", passa a se chamar "Bidê das Velhas". [...] Nenhuma delas, porém, tem o encanto e a variedade de apelidos da praia da Areia Preta, de areia monazidica, reconhecida como eficientíssima no tratamento de artrites, reumatismos e outras doenças de "velho". Repleta principalmente entre 5 e 11 da 
manhã, horas de sol mais fraco, ela exibe uma população alegre, apesar das juntas doloridas, e confiante, apesar da idade média estar sempre acima dos cinquenta anos. Seus apelidos são aceitos com bom humor por seus frequentadores de março: Pelanca Beach Show, praia das Pelancas, praia dos Coroas (VEJA, 1972, p. 47, grifos nossos).

O trecho citado faz uma referência ultrajante aos velhos, objeto de chacota pública. Fica evidente que, em 1972 , era natural que um veículo de comunicação nacional desrespeitasse um segmento da população cujo rebaixamento moral era recebido de forma pacata e recolhida, sem qualquer reação. Tais práticas, no sentido de subestimar os mais velhos, expressam o desrespeito em relação a todos os aspectos do ser - do plano emocional, ao intelectual e material. O pano de fundo desse tipo de abordagem ao velho vai do ato irracional à repulsão, passando pelo questionamento da noção de corpo contemporâneo que nega o tempo e a natureza biológica, não admitindo perdas, fraquezas, mas apostando no reconhecimento do belo e nos padrões de juventude. O poder desse tipo de preconceito dirigido a um grupo etário vulnerável que ocupava um lugar de completa invisibilidade social vem se perpetuando de várias maneiras até os dias de hoje.

$\mathrm{O}$ advento do Estatuto do Idoso e o fortalecimento da institucionalidade e da lei tiveram um caráter fundamental e protetivo. Foi o momento em que o estigma e a discriminação sofridos pelos velhos começou a recuar. Mas mesmo que os mais velhos tenham passado a ser respeitados legalmente e socialmente, não se liquida o preconceito que circula pelos poros da cultura. Basta observarmos que a ciência é obsessiva em não aceitar a velhice, ao tentar manipular os seus genes, prolongar a vida indefinidamente e juvenizar os corpos a qualquer custo (COUTO, 2009, p. 45).

No limiar de um novo processo de envelhecimento, a construção social do sujeito que envelhece vai favorecer 
a construção de uma outra identidade, condição fundamental para permitir uma nova experiência, visibilidade e conexão com o mundo.

Os estereótipos do abandono e da solidão, que caracterizam a experiência de envelhecimento, são substituídos pela imagem dos idosos como seres ativos, capazes de oferecer respostas criativas ao conjunto de mudanças sociais que redefinem essa experiência (DEBERT, 1997, p. 8).

À medida que uma nova narrativa sobre a velhice começa a se impor e novas práticas são acionadas, outro repertório de problemas se estabelece.

A terceira idade emerge e se enlaça às demandas por acolhimento. Um mundo sensivel e afetos distintos são encampados por um universo de novas sociabilidades. Aquele que envelhece passa a se produzir como sujeito social que vê repercutir as práticas deflagradas pelas politicas públicas. Cria-se o idoso saudável, o idoso ativo e, finalmente, o idoso consciente dos seus direitos, mas cuja autonomia e liberdade ainda são um alvo distante.

No dia 17 de novembro de 1976, a Revista Veja publica uma matéria de três páginas, "Vivendo a terceira idade":

Desde o dia 3, todas as pessoas com mais de 60 anos, residentes na cidade de Maringá, no norte do Paraná, têm entrada franca em sessões de cinema, jogos de futebol, circos, parques e canchas de bocha. A decisão partiu do prefeito Sílvio Barros e não tem, segundo ele garante, objetivos eleitorais. Sua adesão à causa dos idosos remontaria a um seminário de gerontologia realizado há alguns meses em São Paulo, do qual Barros participou (VEJA, 1976b, p. 93).

Os primeiros sinais da chegada da terceira idade são registrados e divulgados pela Revista Veja, deixando antever a emergência dos valores de liberdade, dignidade e 
autonomia revisitados, segundo a lógica dos grupos que vão compartilhar e potencializar novas performances e valores etários a partir de então.

Em Recife, uma das integrantes do Programa de Assistência aos Idosos escreveu o trecho do seguinte depoimento:

Aqueles que vivem marginalizados pela sociedade, aqueles que se constituem num peso para a família, podem ainda encontrar seu ponto de apoio moral, espiritual e voltar a se sentirem úteis, valorizados, gente (VEJA, 1976b, p. 96).

Observa-se que, nesse momento, a ideia da existência de uma terceira idade, entendida como fase da vida propícia a redescobertas para o idoso, já constitui um descolamento da percepção de perdas, incapacidades e declínio presentes na topografia de infelicidade prevista na velhice. Assim, uma onda de positividade e esperança ganha espaço no território de cerceamento existente nas poderosas entrelinhas da velhice.

Na matéria "Para maior de 59" (VEJA, 1976a, p. 61), descreve-se assim o clima da nascente terceira idade.

Durante os encontros, num clima frequentemente brincalhão de mútuas provocações, os anciãos dedicam-se a vários campos, que vão desde o artesanato, trabalhos manuais, edição de um jornal - Impacto - jogos, até o planejamento de excursões e discussão sobre a programação do próprio lazer (VEJA, 1976a, p. 61).

A mudança de status de um grupo etário quantitativamente crescente e cada vez mais expressivo evidencia uma terceira idade promotora de uma fase da vida reservada à satisfação pessoal, ainda que mais tarde essa 
equação se desdobre com problemas de dificil solução ${ }^{3}$. Veja acompanha esse momento de implantação de novos padrões que não se instauraram sem conflitos, traumas e novas demandas politicas e sociais, mas representaram a tentativa de desvincular rigidos moldes familiares, afirmando a capacidade intelectual e a autonomia como valores da terceira idade. "Os idosos estão reivindicando uma nova colocação social: o direito de serem eles mesmos" (VEJA, 1976b, p. 93).

\section{Sexualidade e envelhecimento: "não se deixa de amar"}

A partir dos anos setenta, se evidencia um movimento de inclusão da temática da sexualidade de homens e mulheres idosos nos campos da saúde e, mais discretamente, na mídia. Ressalta-se que a sociedade, de modo geral, ainda "percebe os velhos, particularmente as mulheres, como seres assexuados" (MOTTA, 1998, p. 15). Assim, nota-se a permanência de diversos estereótipos em relação à velhice; entre eles, concebe-se a velhice associada à solidão, na qual idosos e idosas não possuem vida sexual nem podem expressar a sua sexualidade. Segundo Debert e Brigeiro (2012), tal discurso sobre a assexualidade dos velhos também fez parte, durante algum tempo, do repertório de alguns especialistas, enquanto outros buscaram "demonstrar que o curso da vida sexual não se extingue ao longo dos anos” (DEBERT; BRIGEIRO, 2012, p. 39).

3 O sonho da realização e satisfação pessoal tem passado por uma série de desafios, como a pedagogização do envelhecimento que tem tentado conduzir a questão de "como deve ser a experiência de ser velho e o que fazer depois dos sessenta", o que tem levado à uniformização de condutas, atitudes e comportamentos, além do controle e monitoramento de vícios, estéticas corporais, sexualidade, consumo e saúde. 
Assim, nota-se a existência de discursos em dois âmbitos: um que relega a velhice à assexualidade e outro que busca demonstrar que envelhecer não significa deixar de exercer a sexualidade. De acordo com Motta (1998), no entanto, "caberia pensar em que medida essa "descoberta da sexualidade" dos velhos não implica a constituição de uma "rede de poder sobre a velhice"” (MOTTA, 1998, p. 26), uma vez que o sexo pode passar a ser mais uma forma de assujeitamento e controle sobre os mais velhos, sendo incluído como mais um elemento da promoção da saúde na terceira idade e na construção da imagem de uma velhice ativa e bem-sucedida. Dessa forma, "uma velhice sexualmente ativa vem se estabelecendo como um ideal defendido por gerontólogos e outros especialistas afins ao tema” (DEBERT; BRIGEIRO, 2012, p. 38).

Assim, observa-se o surgimento desse discurso médico que sustenta a continuidade da prática sexual também na fase da velhice. Em uma reportagem da Revista Veja referente a uma pesquisa realizada nos Estados Unidos sobre a sexualidade na vida adulta, uma psicóloga afirma que "não há razão para que homens e mulheres não possam ter vidas sexuais felizes até muito depois dos oitenta anos, desde que sejam razoavelmente sadios e tenham um parceiro interessado e interessante" (VEJA, 1970, p. 63). O discurso gerontológico afirma que "a sexualidade não se esgota na velhice, mas, pelo contrário, é nesse momento que ela poderia ser vivida em sua plenitude e experimentada de maneira igualitária entre os parceiros" (DEBERT; BRIGEIRO, 2012, p. 49).

O sexo é posto como um meio, uma oportunidade para "transformar a triste e passiva espera do fim numa conquista saudável e construtiva" (VEJA, 1971, p. 64). Evidencia-se assim o que Debert e Brigeiro (2012) denominam de "processo de erotização da velhice":

O discurso dos especialistas inclui a sexualidade como um dos pilares do "envelhecimento ativo", 
modelo de gestão do envelhecimento mais generalizado no mundo contemporâneo. Além de argumentarem sobre a possibilidade de se praticar o sexo até o fim da vida, gerontólogos e sexólogos descrevem-no como uma atividade benéfica para o envelhecimento bem-sucedido (DEBERT; BRIGEIRO, 2012, p. 37).

O sexo torna-se objeto do saber gerontológico, colocado como uma forma de melhorar os aspectos ou tendências negativas associadas à velhice trazendo, inclusive, bons resultados para a saúde dos idosos. Não é rara a comparação entre velhice e juventude - ou entre velhos e jovens:

Na sua maioria, eles são desempregados, de caráter introspectivo e muitas vezes indiferente. Seus corpos e cérebros vivem um rápido e violento processo de transformação. Suas famílias lhes desaprovam as atitudes menos ousadas - de uma viagem solitária até o casamento. E uns e outros estão, permanentemente, obcecados pelo passar do tempo. Para a sociedade, contudo, os jovens representam engrenagens polidas, prontas para o uso. Os velhos, ao contrário, são tão obsoletos quanto uma caravela na travessia do oceano, tão deslocados nos ambientes sociais como um analfabeto numa reunião de intelectuais (VEJA, 1971, p. 64)

A prática sexual é colocada, portanto, como uma prática rejuvenescedora, uma vez que pode ter como resultados "inclusive, rejuvenescer alguns velhos - porque aumenta o entusiasmo pela vida, facilita a circulação sanguínea, melhora a produção glandular e reforça o instinto de sobrevivência" (VEJA, 1971, p. 64).

Por fim, nota-se que o sexo é também defendido como um direito dos mais velhos, como um modo de agir contra a solidão, sendo o etarismo uma das causas do preconceito contra a prática sexual nessa fase da vida, principalmente por parte da família (VEJA, 1971). 


\section{Gerontologia, rejuvenescimento e saúde: a fór- mula de uma Nova Velhice}

Nos primeiros anos da década de 70 e 80, quando as politicas de integração da velhice passam a se interessar pelo bem-estar do sujeito idoso na área da saúde, gerontologia e geriatria avançam na construção de uma nova velhice. Transformações no corpo, lazer, costumes e novos looks voltados para a realização pessoal criam estilos de vida para a população com mais de 60 anos. Nesse contexto, a saúde assistia a uma ampliação de sua interferência sobre o envelhecimento, ao reunir medicina e ciência numa cruzada pelo rejuvenescimento. Debert (1997, p.4142) destaca que a "promessa da eterna juventude é um mecanismo fundamental de constituição de mercados de consumo". E, de fato, a faixa etária que mais cresceu na sociedade, os maiores de 60 anos, passou a movimentar cifras impensáveis, não apenas dinheiro, mas desejos, preferências e exigências, até então inexistentes no mercado.

Nesse período, a literatura internacional já apontava para o fato de que tanto a geriatria quanto a gerontologia não dispunham de uma conceituação clara nem de limites capazes de descrever tal campo de saber "como uma ciência do envelhecimento" (PRADO; SAYD, 2006, p. 493).

Tais questões são elucidativas para a compreensão de uma série de matérias publicadas a partir do ano de 1973 pela Revista Veja, nos meses de fevereiro, março, abril e maio, todas voltadas para a divulgação dos trabalhos do Instituto Geriátrico Otoponi, em Bucareste, Romênia, sob a direção da Dra Anna Aslan, responsável pela descoberta de um medicamento que supostamente eliminaria ou retardaria a senilidade (VEJA, 1973a, 1973b, 1973c, 1973d). O medicamento prometia não apenas a melhoria do estado geral do paciente, mas a cura de vários males, como úlceras no duodeno, asma, aumento da libido, crescimento e restituição da cor natural dos cabelos, 
diminuição ou desaparecimento das rugas. Por isso, segundo a ampla publicidade do Instituto esse medicamento ficou conhecido como "elixir da juventude", popularmente chamado Gerovital. À base de procaína ou lidocaína, esse "super remédio" era chamado no Brasil de KH3 ou KH4, tendo sido consumido por idosos do mundo inteiro. Ainda segundo a matéria publicada na Veja, a droga foi proibida na Itália, no Brasil, restrita nos Estados Unidos, passando a ser contrabandeada e falsificada nesse período. Como declarou nesta edição o biólogo inglês Alex Comfort, "A procaína, base do Gerovital, é um antidepressivo e não um medicamento antivelhice" (VEJA, 1973a, p. 51). Mesmo assim, para além das críticas, as atividades da clínica perpetuam-se até hoje, devido ao fetiche causado pelo desejo da eterna juventude.

Dando continuidade às notícias sobre as atividades duvidosas praticadas na área da geriatria, sob o título "Férias no Hospital", Veja mostra o turismo dos brasileiros cujo destino era a Romênia, mais especificamente, o desejo de realizar um tratamento na clinica geriátrica Otoponi (VEJA, 1973b, p. 53):

O hospital é o Sanatório de Geriatria Otoponi, a $16 \mathrm{Km}$ de Bucareste, numa área de 30 alqueires de parques naturais. E nele trabalham a Dra Aslan e seus assistentes, responsáveis pela descoberta do Gerovital H3, conhecido pelos bons resultados que tem obtido no rejuvenescimento de pessoas idosas (VEJA, 1973b, p. 53).

A matéria sobre a excursão que levaria os brasileiros a fazer o tratamento, pagando doze mil cruzeiros, descreve como os participantes seriam alojados nos hotéis, qual a programação turística em Bucareste e como ocorreriam as aplicações do Gerovital. As visitas à clínica teriam o objetivo de controlar "o crescimento do número de anticorpos na corrente sanguínea", o que "levaria ao rejuvenescimento" (VEJA, 1973b, p. 53). 
Chama a atenção que numa edição anterior, a Revista Veja havia citado o trecho de um relatório da Food and Drugs Administration dos Estados Unidos, órgão controlador das licenças para medicamentos:

Não foi apresentada nenhuma prova que garanta que a procaina (principal componente da droga) permaneça ativa no organismo e seja capaz de produzir algum efeito terapêutico contra o processo de envelhecimento, declarou o relatório de 1970 (VEJA, 1973a, p. 50).

Focalizado de forma pouco crítica, o tema do rejuvenescimento mostrado por Veja, ainda assim dá a ver o oportunismo, a manipulação e a irresponsabilidade que a indústria de medicamentos, a serviço de setores da medicina formal, realizava na época. Ao ser noticiada quatro vezes na década de 70 pela revista, a clínica Otoponi aparece como instituição privilegiada pela fama internacional e prestígio obtido pelo crescente interesse da mídia.

Desde os anos 70, episódios enganosos sobre a promessa do rejuvenescimento foram naturalizados nos meios de comunicação. A fantasia da juventude a qualquer preço que sempre assediou a sociedade fez com que tanto a gerontologia quanto a geriatria perdessem de vista o seu foco denunciar os maus-tratos aos idosos e fomentar o envelhecimento bem-sucedido (DEBERT, 2000, p. 150).

Mesmo a fragilidade e as suspeitas que recaem sobre uma droga "cura-tudo" não foram suficientes para a desaprovação popular do Gerovital. Esse elixir da juventude foi fundamentado pela suposta excelência de médicos famosos e encoberto pela clínica Otoponi - conceituada internacionalmente por pacientes que foram celebridades de época como Salvador Dali, Charles De Gaulle, John Kennedy, 
Sophia Loren, Greta Garbo e Charlie Chaplin, entre outros ${ }^{4}$.

Uma enorme exigência por rejuvenescimento acompanhava a sociedade na transformação de seus referenciais de envelhecimento. A vida para aqueles com mais de 60 anos tornou-se um labirinto de novas dúvidas, descobertas e inconstâncias. A excitação com o cotidiano veio a produzir novas relações com o corpo e com o outro, transformando a visão de mundo daquele que envelhecia. Rejuvenescimento e saúde passaram a ser objeto do discurso sobre envelhecimento saudável, na tentativa de potencializar as condições de vida dos mais velhos, enquanto a geriatria dava seus primeiros passos no Brasil.

Em 1974, Veja noticia, sob o título "Hospital de Velhos", a "criação do primeiro hospital brasileiro para pesquisa e tratamento de pessoas idosas" (VEJA, 1974, p. 70). O Hospital Piloto de Geriatria, com capacidade para 120 leitos, projeto do médico Tuffik Mattar, localizado em um dos pavilhões do Hospital Juqueri, desde a publicação da matéria, estava funcionando há três meses graças às doações externas e muito dinheiro que vinha do bolso de seu idealizador. A finalidade científica do hospital foi questionada ao longo da matéria, uma vez que seria necessário para pesquisa e desenvolvimento dos estudos "dez casos para cada tipo de doença" e só havia 23 mulheres e 19 homens internados. Ainda assim, era previsto o tratamento gratuito das doenças, porém "após quatro meses, no entanto, curados ou não, os pacientes recebiam alta e eram substituídos por outros" (VEJA, 1974, p. 70).

O momento da criação das primeiras clínicas geriátricas no país estabelece novas condutas, comportamentos e modos de vida que visavam a garantia de saúde e longevidade. A vida passava a ser planejada segundo as metas do

4 Fonte: <http://gerovital-online.com/ro/content/15-ana-aslan>. Acesso em: 14 set. 2016 . 
conhecimento médico. Surgiam os individuos obedientes às normas que garantem a saúde. A busca do cuidado corporal, higiênico e alimentar torna-se uma necessidade baseada na visão biológica do envelhecimento e na tentativa de pausar a morbidade e a incapacidade física na velhice. A ciência e a técnica investidas na área da saúde passam a atuar sobre o prolongamento da vida, o que leva ao surgimento de uma maior medicalização da velhice. No entanto, esse periodo inicial da geriatria transita da preocupação com a doença para uma perspectiva de auto expressão da velhice que vai deixar de ser dramática para se constituir objeto exclusivo de especialistas. Uma aura de cientificidade somava-se a defesa de um estilo de vida jovem na velhice, fazendo com que a geriatria e a gerontologia se perfilassem com a ideologia da velhice bem-sucedida.

O contraste entre representações distintas do envelhecimento e o interesse social pelas tecnologias de rejuvenescimento leva os gerontólogos a negarem o seu próprio objeto de estudo e intervenção. De participantes ativos na transformação do idoso em um ator politico, vêem-se transformados, especialmente pela mídia, em divulgadores de uma parafernália de receitas a indicar como os que não querem ser velhos devem agir (DEBERT, 1997, p. 11).

A gerontologia conduziu ao estudo dos processos de envelhecimento, mas ao assumir uma característica multidisciplinar, mimetizou-se com a terceira idade, praticamente confundindo-se com a sua emergência e desenvolvimento. Enquanto categoria transetária, a terceira idade vai amparar-se no discurso da gerontologia social, na especialização da gestão do envelhecimento e nos interesses de uma cultura do consumo (SILVA, 2008, p. 155).

A terceira idade se estabeleceu na medida em que os mais velhos se distanciaram dos estereótipos depreciativos da velhice, passando a valorizar os padrões estéticos 
e a saúde, uma agenda contínua de atividades, tudo isso coroado por uma postura de inserção no mundo do consumo contemporâneo.

Ou seja, a velhice se transformou na medida em que as novas representações estabeleceram conexão com a ideia de valorização da juventude, da sexualidade, dando centralidade a uma imagem e estética corporais.

Nesse sentido, o envelhecimento está circunscrito às relações entre subjetividade, sociedade e multidimensionalidade, remetendo a diversas trocas com um mundo onde todos querem se incluir. É isso o que pode explicar os processos de recusa da velhice ocorridos em toda extensão da vida social, tornando-se fenômeno expressivo, principalmente entre os velhos.

Parece humilhante deixar de ser jovem e ingressar naquele período da vida em que os mais complacentes nos olham com piedade e simpatia, para não utilizar a palavra ofensiva velhice preferem o eufemismo terceira idade (KEHL, 2004, p. 89).

O que não se podia imaginar é que essa recusa da velhice avançaria como fenômeno social, sucateando a ideia de velhice e tornando a juventude uma fórmula quase exclusiva de inclusão na realidade.

\section{Considerações finais}

Quando se trata de envelhecimento, a função expressa pela mídia é valiosa, ao transformar-se em parâmetro para aqueles que envelhecem, formatando práticas, atitudes e influenciando o olhar de todas as faixas etárias sobre aquilo que deve ser envelhecer.

Observa-se que em poucas décadas, o velho deixa um "não lugar" simbólico e passa a ocupar um território 
compativel com um grupo etário numeroso no país, dotado de poder aquisitivo e pronto para fazer escolhas baseadas numa perspectiva realista em direção ao prolongamento da vida. É fato que os maiores louros da terceira idade são colhidos pela classe média. Os clubes da terceira idade são um fenômeno planetário, levam o carimbo dos extratos medianos da população e por isso mesmo ainda assistem circular a desigualdade entre os que envelhecem. Velhos pobres permanecem invisiveis, onde sempre estiveram, partilhando as condições de pobreza nas estatísticas oficiais e usufruindo de poucas conquistas da terceira idade.

O velho, a velhice e a terceira idade como representações recuam, arrefecem, perdem a intensidade quando nosso olhar busca a homogeneidade como principio ordenador do envelhecer. Vibrante é quebrar o antigo disciplinamento social dos mais velhos, recolocando o corpo na cultura, um corpo moldável, a ser refeito. Tudo isso gera "uma preocupação consigo mesmo que se traduz na atualidade como atenção a um corpo desenhado à medida pelo sujeito" (ORTEGA, 2006, p. 89).

Escapar da velhice ao acreditar no rejuvenescimento como item civilizador obrigatório faz parte de uma visão estereotipada que não cabe na ideia de multirreferencialidade imposta por uma cultura do envelhecer que emerge lado a lado à rápida sucessão das gerações e seus polimorfismos culturais inesperados.

Independente da sucessão de lógicas conservadoras, a diversidade também prospera. Talvez, no futuro próximo, rejuvenescer possa ser considerado apenas um fenômeno retrógrado, algo que aponte para uma volta no tempo sem importância ou interesse para efeito da realidade comum. Isto porque o questionamento dos sentidos de envelhecer tem apontado em direção à experiência e aproveitamento real das coisas boas da vida. Novas formas de criar, ver e viver a realidade estão sendo possibilitadas 
a quem envelhece através de pertencimento social, inclusão, reconhecimento, o que leva ao ultrapassamento dos limites convencionais impostos nos dias atuais aos mais velhos.

É assim que o advento da terceira idade, cujas dimensões permitem acesso ao mundo e a seus novos experimentos, enuncia o corpo como libertação individual e coletiva, mas também supõe disciplinamento compartilhado no plano dos gostos, costumes, constituindo-se eventualmente como lugar de prisão e alienação. 


\section{Referências}

COUTO, E. S. Uma estética para corpos mutantes. In: COUTO, E. S. E; GOELLNER, S. V. (Orgs.). Corpos Mutantes: ensaios sobre novas (d)eficiências corporais. Porto Alegre: UFRGS Editora, 2009. p. 41-54.

DEBERT, Gita Grin. A Invenção da Terceira Idade e a Rearticulação de Formas de Consumo e Demandas Políticas. Revista Brasileira de Ciências Sociais, São Paulo, v. 12, n. 4, p. 39-56, jun. 1997.

DEBERT, G. G. A invenção da terceira idade e a rearticulação de formas de consumo e demandas políticas. Revista Brasileira de Ciências Sociais, São Paulo, v. 12, n. 34, p. 1-18, jun. 1997. Disponivel em: <http://www.anpocs.org. br/portal/publicacoes/rbcs_00_34/rbcs34_03.htm>. Acesso em: 14 set. 2016.

. O significado da velhice na sociedade brasileira. Acta Paulista de Enfermagem, São Paulo, Número Especial, v.13, p. 147-158, 2000.

BRIGEIRO, M. M. C. Fronteiras de gênero e sexualidade na velhice. Revista Brasileira de Ciências Sociais, São Paulo, v. 27, n. 80, 2012. p. 37-54.

JUNQUEIRA, L. Noção de representação social na sociologia contemporânea. Estudos de Sociologia, Araraquara, n.18/19, p. 145-161, 2005.

KEHL, M. R. A juventude como sintoma da cultura. In: NOVAES, R; VANNUCHI, P. (Orgs.). Juventude e Sociedade: Trabalho, Educação, Cultura e Participação. São Paulo: Fundação Perseu Abramo, 2004. p. 89-114.

MOTTA, F. M. Introdução. In: Velha é a vovozinha: identidade feminina na velhice. Santa Cruz do Sul: EDUNISC, 1998. p. 13-22. 
ORTEGA, F. Das utopias sociais corporais às utopias corporais: identidades somáticas e marcas corporais. In: Culturas Jovens: novos mapas de afeto. ALMEIDA M. I; EUGENIO, F. (Orgs.). Rio de Janeiro: Zahar, 2006. p. 42-58.

PRADO, S. D; SAYD, J. D. A gerontologia como campo do conhecimento científico: conceito, interesses e projeto político. Ciência \& Saúde Coletiva, Rio de Janeiro, n.2, v.11, p.491-501, 2006.

SILVA, L. R. F. Da velhice à terceira idade: o percurso histórico das identidades atreladas ao processo de envelhecimento. História, Ciências, Saúde, Manguinhos, v. 15, n. 1, p. 155-168, jan./mar. 2008.

VEJA. O sexo adulto. Editora Abril, ed. 70, 1970, p. 63. Disponivel em: <https://acervo.veja.abril.com.br/>. Acesso em: 17 abr. 2013.

VEJA. Sexo na velhice. Editora Abril, ed. 133, 1971, p. 6465. Disponivel em: <https://acervo.veja.abril.com.br/>. Acesso em: 23 mai. 2013.

VEJA. Um mês de verão só para velhos. Editora Abril, ed. 185, 1972, p. 47-50. Disponivel em: <https://acervo.veja. abril.com.br/>. Acesso em: 23 mai. 2013.

VEJA. Os velhos novos. Editora Abril, ed. 232, 1973a, p. 50-51. Disponivel em: <https://acervo.veja.abril.com.br/>. Acesso em: 17 abr. 2013.

VEJA. Férias no hospital. Editora Abril, ed. 237, 1973b, p. 53-54. Disponivel em: <https://acervo.veja.abril.com.br/>. Acesso em: 17 abr. 2013.

VEJA. Cerco à velhice. Editora Abril, ed. 252, 1973c, p. 49. Disponivel em: <https://acervo.veja.abril.com.br/>. Acesso em: 17 abr. 2013. 
VEJA. Ave Aslan. Editora Abril, ed. 274, 1973d, p. 34. Disponivel em: <https://acervo.veja.abril.com.br/>. Acesso em: 6 nov. 2013.

VEJA. Hospital de velhos. Editora Abril, ed. 305, 1974, p. 70. Disponivel em: <https://acervo.veja.abril.com.br/>. Acesso em: 7 nov. 2013.

VEJA. Vivendo a terceira idade. Editora Abril, ed. 428, 1976a, p. 93-94. Disponível em: <https://acervo.veja.abril. com.br/>. Acesso em: 7 nov. 2013.

VEJA. Para maior de 59. Editora Abril, ed. 389, 1976b, p. 61. Disponível em: <https://acervo.veja.abril.com.br/>. Acesso em: 8 out. 2013. 


\section{ANEXO A: TABELAS}

TABELA 1 - Reportagens da Revista Veja coletadas com a temática "emergência da terceira idade"

\begin{tabular}{|l|c|c|}
\hline \multicolumn{3}{|c|}{ Emergência da "terceira idade" } \\
\hline \multicolumn{1}{|c|}{ Título } & Data de publicação & Edição \\
\hline Um mês de verão só para velhos & $22 / 03 / 1972$ & Ed. 185 \\
\hline Vivendo a terceira idade & $17 / 11 / 1976$ & Ed. 428 \\
\hline Para maior de 59 & $18 / 02 / 1976$ & Ed. 389 \\
\hline
\end{tabular}

Fonte: Elaboração das autoras.

TABELA 2 - Reportagens da Revista Veja coletadas com a temática "fórmulas contra o envelhecimento - ciência e medicina"

\begin{tabular}{|l|c|c|}
\hline \multicolumn{2}{|c|}{ Fórmulas contra o envelhecimento - ciência e medicina } \\
\hline \multicolumn{1}{|c|}{ Título } & Data de publicação & Edição \\
\hline Os velhos novos & $14 / 02 / 1973$ & Ed. 232 \\
\hline Férias no hospital & $21 / 03 / 1973$ & Ed. 237 \\
\hline Cerco à velhice & $05 / 07 / 1973$ & Ed. 252 \\
\hline Ave Aslan & $05 / 12 / 1973$ & Ed. 274 \\
\hline Hospital de velhos & $10 / 07 / 1974$ & Ed. 305 \\
\hline
\end{tabular}

Fonte: Elaboração das autoras.

TABELA 3 - Reportagens da Revista Veja coletadas com a temática "sexualidade e velhice"

\begin{tabular}{|l|c|c|}
\hline \multicolumn{3}{|c|}{ Sexualidade e velhice } \\
\hline Título & Data de publicação & Edição \\
\hline O sexo adulto & $27 / 05 / 1970$ & Ed. 70 \\
\hline Sexo na velhice & $24 / 03 / 1971$ & Ed. 133 \\
\hline
\end{tabular}

Fonte: Elaboração das autoras. 